\title{
Laser Doppler flowmetry is useful in the clinical management of small bowel transplantation
}

\author{
E J Corbett, B N Barry, S G Pollard, J P A Lodge, M C Bellamy, and on behalf of the Liver \\ Transplant Group
}

\begin{abstract}
Objective-Laser Doppler flowmetry (LDF) has been used as a research tool to measure splanchnic perfusion. In this report, we aim to demonstrate the clinical value of this technique in perioperative monitoring of transplanted small bowel.

Methods-A 24 year old man underwent small bowel transplantation using a previously described technique. Microvascular blood flow in the transplanted bowel was measured using an LDF splanchnic probe. Postoperatively this was applied to the stoma facilitating direct measurements of graft mucosal flow. Measurements (perfusion units (PU)) were documented prior to implantation, post-reperfusion, postoperatively, during graft ischaemia, and in response to therapeutic interventions (dopexamine and phenylephrine infusions).
\end{abstract}

Results-Prior to transplantation, biological zero was established. Flow at five, 15 , and 60 minutes after reperfusion was 74 (1.9) PU, 87.5 (3.3) PU, and 141.5 (2.5) PU, respectively. Postoperative mucosal flow was 141.6 (2.9) PU. Subsequent LDF measurement detected absence of flow even though clinical signs suggested only moderate reduction. This was confirmed on surgical re-exploration and facilitated prompt resection of a non-viable segment. Fluid and dopexamine administration resulted in a dose dependent improvement in flow, independent of blood pressure. Addition of phenylephrine increased total mucosal flow and unmasked a cyclical component.

Conclusion-This case demonstrates the clinical value of $\mathrm{LDF}$ as an "alarm" to indicate graft perfusion failure and as a monitor for therapeutic interventions. Phenylephrine and dopexamine may both be of value in improving mucosal flow in the transplanted small bowel.

(Gut 2000;47:580-583)

Keywords: laser Doppler; small bowel transplantation; mucosa; dopexamine; flow motion phenomenon

The use of laser Doppler flowmetry (LDF) has been validated as a method for measuring gastrointestinal mucosal microvascular blood flow in animal models, ${ }^{12}$ in human volunteers, and in clinical studies. ${ }^{34}$ The technique has been found to be useful as a predictor of small bowel graft survival in animals. ${ }^{5}$

We report the first use of LDF with a major clinical application in human small bowel transplantation. LDF was used to optimise vasopressor and inotropic drugs in the perioperative period.

\section{Case report}

A 24 year old man with Gardner's syndrome ${ }^{6}$ presented with intestinal failure. $\mathrm{He}$ had undergone a restorative proctocolectomy six years previously and remained well for two years before developing abdominal pain and weight loss. A large unresectable desmoid tumour involved the entire small bowel mesentery. Single agent chemotherapy with doxorubicin gave a good clinical response.

Three years later he again presented with similar symptoms, this time caused by infarction of the entire small bowel. Following total enterectomy the patient was maintained on parenteral nutrition for 18 months pending assessment for small bowel transplantation. At the time of transplantation there was evidence of parenteral nutrition related cholestasis (pretransplant blood analysis showed bilirubin 132 $\mu \mathrm{mol} / 1$, alanine transaminase $280 \mathrm{iu} / 1$, alkaline phosphatase $611 \mathrm{iu} / 1$, and prothrombin time 13 seconds) although this was not sufficiently severe to warrant simultaneous liver transplantation.

MATERIALS AND METHODS

Preoperative assessment included echocardiogram and magnetic resonance angiography of splanchnic vessels and a full metabolic/ nutritional and psychological profile according to the UK Departments of Health protocol (D Shaffer, data on file, Departments of Health, Wellington House, London, UK).

Anaesthesia was induced with midazolam $7.5 \mathrm{mg}$, alfentanil $7.5 \mathrm{mg}$, and atracurium $50 \mathrm{mg}$. The trachea was intubated and the lungs ventilated to normocapnia; anaesthesia

Abbreviations used in this paper: $\mathrm{LDF}$, laser Doppler flowmetry; PU, perfusion units; MMC, migrating motor complex. 


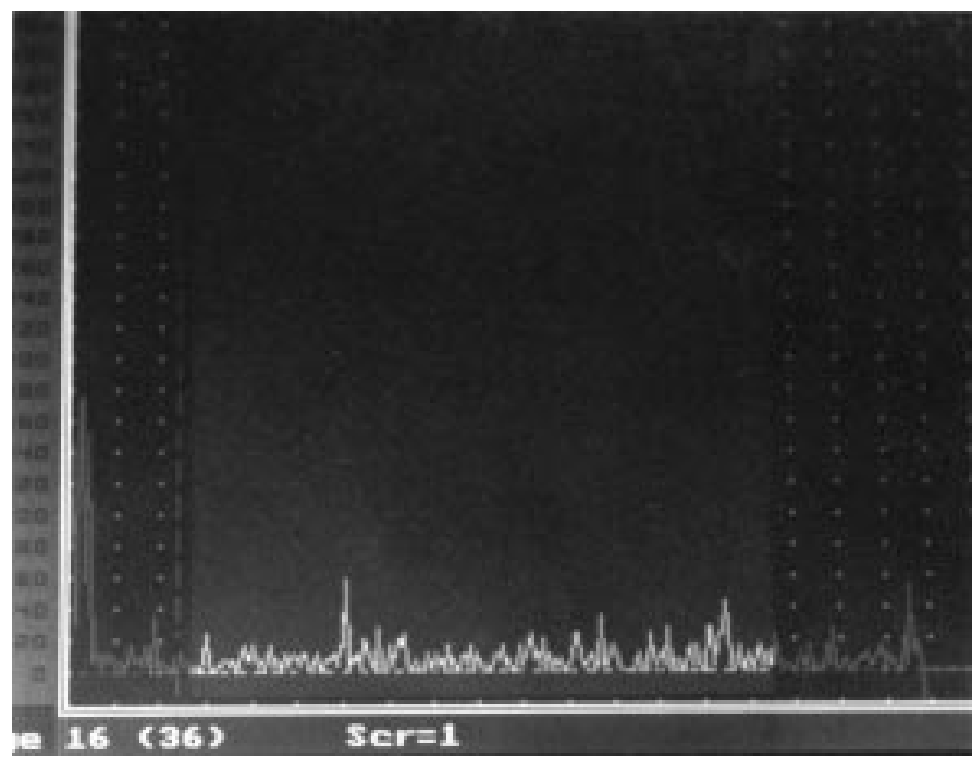

Figure 1 Laser Doppler flowmetry (LDF) record (in perfusion units/time) of graft microvascular blood flow at baseline.

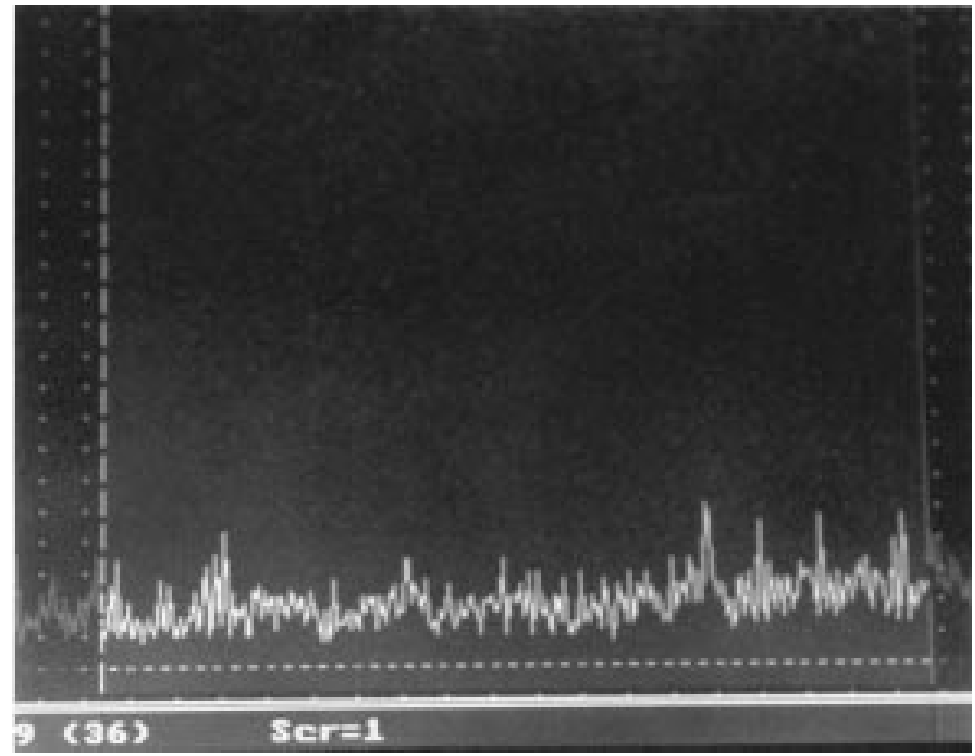

Figure 2 Laser Doppler flowmetry ( $L D F)$ record at the time of critical graft ischaemia. Blood flow approaches previously determined biological zero (horizontal dashed line indicates biological zero flow).

was maintained with desflurane (1 MAC) in oxygen enriched air, alfentanil $1.5 \mathrm{mg} / \mathrm{h}$ and atracurium $30 \mathrm{mg} / \mathrm{h}$ as previously described. ${ }^{7}$ Invasive monitoring was used, including arterial and central venous pressure measurement and a pulmonary artery catheter (mixed venous oxygen saturation and right ventricular ejection fraction). A 12 French gauge triple lumen central venous catheter (Certofix Trio V1215, B Braun, Melsungen, Germany) was connected to a Level 1 System 1000 infusion device (SIMS Level 1 Inc., Rockland, Massachusetts, USA) for rapid transfusion. This allowed transfusion of fluids warmed to $37^{\circ} \mathrm{C}$ at up to $600 \mathrm{ml} / \mathrm{min}$.

The standard surgical technique for small bowel transplantation in our centre has previously been described. ${ }^{8}$ After mobilisation of the donor small bowel from the duodenojejunal flexure to the terminal ileum on its mesentery, the superior mesenteric vessels were dissected out. The graft was perfused with University of Wisconsin solution before stapling and dividing the bowel ends and blood vessels. The recipient's remaining native bowel was mobilised along with the infrarenal abdominal aorta and portal vein. At implantation, vascular anastomoses were performed first, venous followed by arterial. Bowel anastomoses were then performed; proximal followed by distal with formation of a distal graft enterostomy. A gastrojejunal feeding tube was inserted via a gastrostomy and fed into the grafted small bowel.

Antibiotic prophylaxis was given to both donor and recipient. Selective decontamination of the digestive tract (colistin, neomycin, amphotericin, and nystatin) was given to the recipient, starting immediately after surgery. Immunosuppression was commenced at surgery with tacrolimus, methylprednisolone, and mycophenolate mofetil. Dopexamine $1 \mu \mathrm{g} / \mathrm{kg} / \mathrm{min}$ was infused to optimise graft perfusion.

Intraoperatively and postoperatively, microvascular blood flow in the transplanted bowel was measured using LDF and a splanchnic flow probe (PF3, Perimed AB, Järfälla, Sweden). We were able to document the effects of vasoactive drugs and other therapeutic manoeuvres on the circulation in the small bowel microvasculature.

LDF uses a helium/neon laser to produce monochromatic light at $632.8 \mathrm{~nm}$ which is transmitted along a $1.75 \mathrm{~m}$ optical fibre. The principle underlying LDF is that light undergoes a Doppler shift when in collision with moving red blood cells. It is reflected along the fibre to two photodetectors that separate light that has undergone a Doppler shift from light reflected from the static tissue matrix. The output voltage varies linearly with the product of mean red blood cell velocity and red blood cell concentration. This is referred to as red cell flux, which is proportional to blood flow at all but very high haematocrits. ${ }^{10}$ The tissue penetration of the laser is approximately 1-3 $\mathrm{mm}$, allowing the study of mucosal or serosal blood flow without interference from the greater muscularis blood flow. ${ }^{1}$

LDF was interfaced with a laptop computer and the signal analysed using the Perisoft version 4.41 software package (Perimed AB, Järfälla, Sweden). Biological zero blood flow measurement was obtained from the small bowel graft prior to implantation. A stable signal of at least 60 seconds duration was then recorded at each measurement point. Intraoperatively, serosal blood flow, which has previously been shown to correlate well with mucosal flow, ${ }^{11}$ was measured. Postoperatively the probe was applied to the stoma, facilitating direct measurement of graft mucosal blood flow. Flow measurements are expressed as mean perfusion units (PU) with standard error over the period of observation.

\section{RESULTS}

Intraoperatively, the use of phenylephrine to treat hypotension was seen to improve microvascular blood flow in the transplanted small bowel. In the immediate postoperative period 


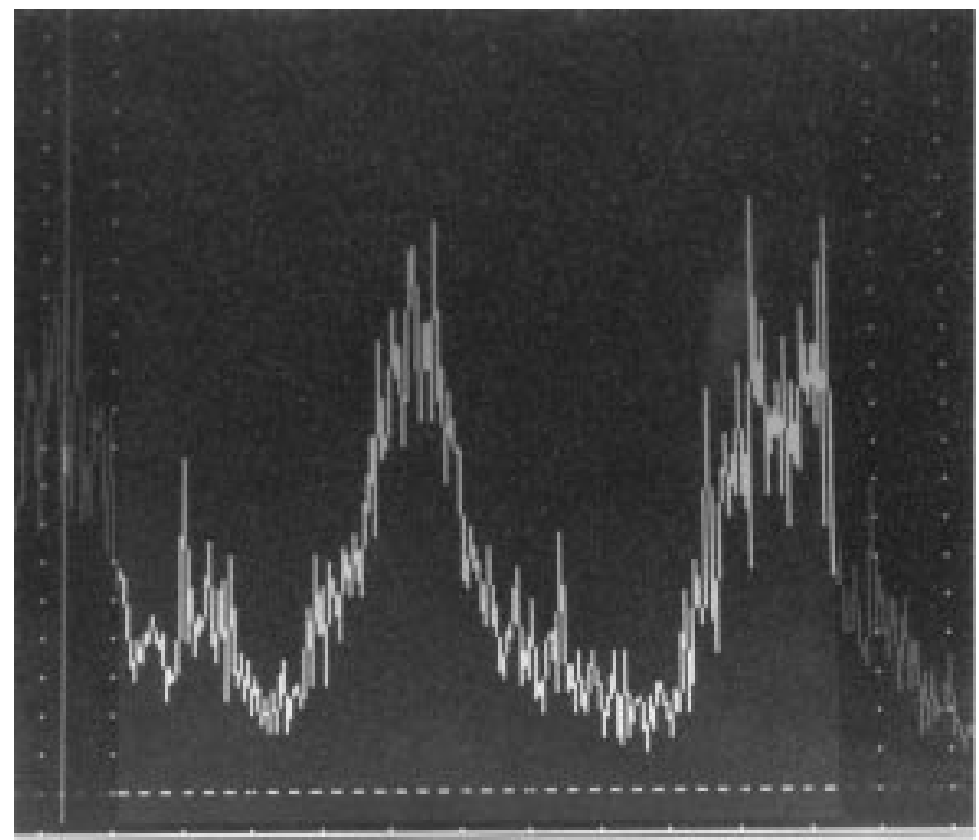

Compress $=2$

Figure 3 Laser Doppler flowmetry (LDF) record following administration of phenylephrine. In addition to an overall increase in graft mucosal blood flow, there is the appearance of a marked cyclical component.

Table 1 Mean (SEM) graft microvascular blood flow measurements (perfusion units $(P U))$ in relation to mean arterial pressure $(M A P)$, arterial $p H$, and cardiac output $(C O)$ following graft reperfusion, during graft ischaemia, and in response to dopexamine and phenylephrine therapy

\begin{tabular}{|c|c|c|c|c|}
\hline Time & Flow (PU) & $\begin{array}{l}M A P \\
(m m H g)\end{array}$ & $p H a$ & $\begin{array}{l}\text { CO } \\
\text { (litre } \mathrm{min} / \mathrm{m}^{2} \text { ) }\end{array}$ \\
\hline Biological zero & $13.5(2.2)$ & 69 & 7.388 & 8.17 \\
\hline 5 minutes post-reperfusion & $74(1.9)$ & 52 & 7.349 & 9.20 \\
\hline 15 minutes post-reperfusion & $87.5(3.3)$ & 65 & & 9.20 \\
\hline 60 minutes post-reperfusion & $141.5(2.5)$ & 50 & 7.377 & 8.27 \\
\hline Postoperative & $141.6(2.9)$ & & & \\
\hline Bowel "dusky" & $7.9(0.6)$ & & & \\
\hline \multicolumn{5}{|l|}{ Dopexamine } \\
\hline Off & $35.6(1.7)$ & & & \\
\hline $1 \mu \mathrm{g} / \mathrm{kg} / \mathrm{min}$ & $60.4(1.4)$ & 70 & & \\
\hline $2 \mu \mathrm{g} / \mathrm{kg} / \mathrm{min}$ & $87.2(2.1)$ & & & \\
\hline \multicolumn{5}{|l|}{ Phenylephrine } \\
\hline Trough & $52.8(2.8)$ & & & \\
\hline Mean & $110.8(3.4)$ & 90 & & \\
\hline Peak & $205.7(7.6)$ & & & \\
\hline
\end{tabular}

the stoma was noted to look dusky and "bruised"; clinically this was thought to indicate a moderate reduction in blood flow. The patient remained systemically well with no evidence of sepsis or haemodynamic instability, although arterial lactate concentration was slightly elevated at $2.0 \mathrm{mmol} / 1$. However, measurements using the laser Doppler probe showed complete absence of microvascular blood flow, in contrast with the baseline trace at the end of surgery (figs 1,2 ).

The patient was immediately returned to the operating room where, on exploration, the distal transplanted bowel was found to be ischaemic, with a clear line of demarcation. This ischaemic segment of graft was resected and the distal anastomosis and stoma were refashioned. This gave a good clinical result, confirmed by good flow on LDF.

Following return to the intensive care unit, the patient required treatment for hypotension. Initial treatment by fluid optimisation and seri- ally increasing the dose of dopexamine led to improvement in LDF flow but not in mean arterial pressure. These trends were identical to those previously described. ${ }^{9}$ Phenylephrine was then given, resulting in an increase in blood pressure, together with the appearance of a cyclical change in blood flow with a marked periodicity (fig 3). Mean (SEM) blood flow measurements associated with these interventions are documented in table 1.

On the eighth postoperative day the patient's condition deteriorated with bilateral basal pneumonia and septicaemia, requiring readmission to the intensive care unit for ventilation and vasopressor support. Again, we were able to monitor microvascular blood flow in the transplanted small bowel using LDF, confirming adequacy of perfusion, and to assess the response to vasoactive drugs. The patient made a good recovery and was discharged to the ward.

\section{Discussion}

There are two findings of interest from this case: firstly, the value of LDF in the diagnosis of critical ischaemia and monitoring graft blood flow in the clinical setting. This may have further applications in the future, for example in conjunction with an endoscope to assess flow at more proximal points; secondly, the unexpected effects of phenylephrine producing a cyclical flow pattern with improved graft perfusion.

Phenylephrine (an $\alpha_{1}$ agonist) is a potent vasoconstrictor conventionally regarded as deleterious to hepatosplanchnic perfusion. Recent studies have challenged this view. ${ }^{12}$ In our study, phenylephrine increased total mucosal flow and induced or unmasked a cyclical component, which resembled previous descriptions of the flow motion phenomenon. Several authors have described the phenomenon of cyclical blood flow changes in the splanchnic circulation during sepsis. This has been termed the "flow motion" phenomenon. Flow motion may be caused by slow wave flow motion in vascular smooth muscle that rhythmically contracts and relaxes with a frequency of 1-3 cycles per minute, which acts to improve tissue perfusion. ${ }^{13}$ This is distinct from studies in animals and human volunteers assessing mucosal flow changes in response to a combination of $\alpha$ and $\beta$ agonists/antagonists ${ }^{1-4}$ which confirmed older studies that showed a period of reduced flow followed by secondary mesenteric dilatation through a mechanism diminished by $\beta$ adrenergic blockade. ${ }^{14}$ The cyclical flow pattern we observed in response to phenylephrine may represent a situation peculiar to transplanted bowel, devoid of external innervation, and call into question the accepted view that $\alpha_{1}$ agonists reduce blood flow.

Another possibility is that periodic variation in blood flow could be mediated by the migrating motor complex (MMC), as seen in healthy gut and previously seen in human volunteers using LDF. ${ }^{3}$ Thollander et al have shown that the highest blood flow occurs during phase 3 of the MMC, during which flow changes with a frequency of 11-12 cycles per minute. 
These data confirm the value of laser Doppler flowmetry as a clinical tool in small bowel transplantation and call into question the traditional views on the role of $\alpha_{1}$ agonists.

We thank St James's special trustees and Baxter Healthcare.

The Liver Transplant Group are: Mr J P A Lodge, Mr S G Pollard, Mr G Toogood, Dr M C Bellamy, Dr Y Yatin, Dr N Snook, Dr M H Davies, and Dr CE Millson.

1 Shepherd AP, Riedel GL. Continuous measurement of intestinal mucosal blood flow by laser-Doppler velocimetry. Am F Physiol 1982;242: G668-72.

2 Feld AD, Fondacaro JD, Holloway GA Jr, et al. Measurement of mucosal blood flow in the canine intestine with laser Doppler velocimetry. Life Sci 1982;31:1509-17.

3 Thollander M, Hellström PM, Svensson TH, et al. Haemodynamic changes in the small intestine correlate to migrating motor complex in humans. Eur $\mathcal{F}$ Gastroenterol Hepatol 1996;8:777-85.

4 Thollander M, Hellström PM, Gazelius B. Semi-invasive laser-Doppler flowmetry technique. New application for recordings of hemodynamics in combination with manometry of human small intestine. Int $\mathcal{F}$ Microcirc Clin Exp 1997; 17:15-21.

5 Yamada T, Taguchi T, Suita S. Energy metabolism and tissue blood flow as parameters for the assessment of graft sue blood flow as parameters for the assessment of graft
viability in rat small bowel transplantation. $\mathcal{F}$ Pediatr Surg 1996;31:1475-81.
6 Gardner EJ. Follow-up study of a family group exhibiting dominant inheritance for a syndrome including intestinal
polyps, osteomas, fibromas and epidermal cysts. Am $\mathcal{F}$ Hum polyps, osteomas, fibrom
Genet 1962;14:376-90.

7 Bellamy MC, Enright SM, Young Y, et al. Living related small bowel transplantation: Anaesthesia and perioperative care. Eur f Anaesthesiol 1997;14:450-4.

8 Lodge JP, Pollard SG, Selvakumar S, et al. Alternative techniques for arterialisation in multivisceral grafting. Transplant Proc 1997;29:1850-2.

9 Bellamy MC, Mullane D, O'Bierne HA, et al. Dopexamine and microcirculatory flow in transplanted small bowel: The Leeds experience. Transplant Proc 1997;29:1847-9.

10 Almond NE, Wheatley AM. Measurement of hepatic perfusion in rats by laser doppler flowmetry. Am 7 Physiol 1992;262:G203-9.

11 Olechristian Lunde. Endoscopic laser Doppler flowmetry in evaluation of human gut blood flow, MD thesis. Oslo: Department of Surgery, Aker Hospital, 1988.

12 Van der Graaf PH, Saxena PR, Shankley NP, et al. Exposure and characterization of the action of noradrenaline at dopamine receptors mediating endothelium-independent relaxation of rat isolated small mesenteric arteries. $\mathrm{Br} f$ Pharmacol 1995;116:3237-42.

13 Erni D, Banic A, Sigurdsson GH, et al. Relationship between arterial pressure and blood flow in the generation of slow-wave flowmotion in rat skeletal muscle. Int 7 Microcirc Clin Exp 1997;17:175-83.

14 Ross G. Effects of epinephrine and norepinephrine on the mesenteric circulation of the cat. Am 7 Physiol 1967;212: $1037-42$. 